\title{
CHARACTERISTIC OF GREEN SYNTHESIZED Ag NANOPARTICLE USING EXTRACT AND ESSENTIAL OIL OF Illicium verum HOOK. F. AS ANTIBACTERIAL
}

\author{
Rizki Damayanti ${ }^{1,2}$, Tamrin ${ }^{1, *}, Z^{\prime}$ Alfian ${ }^{1}$ and Eddiyanto ${ }^{3}$ \\ ${ }^{1}$ Department of Chemistry, Universitas Sumatera Utara, Medan, Indonesia \\ ${ }^{2}$ Department of Chemistry Universitas Serambi Mekkah, Banda Aceh, Indonesia \\ ${ }^{3}$ Department of Chemistry Universitas Negeri Medan, Medan, Indonesia \\ *E-mail: tamrin@usu.ac.id
}

\begin{abstract}
Developing a new method to produce antibacterial material using the green synthesis concept. In this current study, Ag nanoparticle was synthesized based on the green synthesis concept using extract and essential oil of Illicium verum Hook. F. The GC-MS spectrum showed the major components of the essential oil was anethol (96. 83\%). The Ag nanoparticle of extract and essential oil was characterized using FT-IR, XRD, TGA/DTA, TEM. The FTIR spectrum of AgNPsE a new spectrum e.i. at $750 \mathrm{~cm}^{-1}$. The crystallography of XRD AgNPsMA and AgNPsE powder analysis showed a peak at $2 \theta 37^{\circ}(111), 44^{\circ}(200), 64^{\circ}(202)$, and $78^{\circ}(311)$. Both Ag nanoparticles showed a potential antibacterial activity.
\end{abstract}

Keywords: Illicium verum, Ag Nanopaticles, Antibacterial, AgNPsE, AgNPsMA.

(C) RASĀYAN. All rights reserved

\section{INTRODUCTION}

The nanoparticle is a quite famous technology in this era. ${ }^{1}$ Nanomaterial has a different size and properties than the other material. ${ }^{2,3}$ The Ag nanoparticle is one famous nanomaterial with a wide app(location. The nanoparticle is prepared to obtain a special characteristic for the specific purpose of the application. ${ }^{4}$ The Ag nanoparticle has the potential to be used in the magnetic, ${ }^{5}$ and drug delivery. ${ }^{6}$ The specific process to obtain $\mathrm{Ag}$ nanoparticle which economic and friendly environmentally is still on finding. ${ }^{7}$ The $\mathrm{Ag}$ nanoparticle can be prepared through several methods, i.e. chemical, physical, and biological. ${ }^{8}$ Among those methods, green synthesis is the one that can be said as the ecofriendly method. ${ }^{9,10}$ Also stated, ${ }^{4}$ the green synthesis of $\mathrm{Ag}$ nanoparticle is unique to develop due to involve biosynthesis process and ecofriendly. Several studies on the preparation of Ag nanoparticle through green synthesis had been performed, i.e. Ag nanoparticle - Syngonium podophyllium leave extract ${ }^{11}$ has good bioactivity as antifungal, as well as $\mathrm{Ag}$ nanoparticle from Coriandrum sativum ${ }^{12}{ }^{\text {Ocium. }}{ }^{7}$

The green synthesis method focuses on the exploration of natural product potency as a precursor or template to synthesis Ag nanoparticles. ${ }^{9,13-18}$ In this study, an Ag nanoparticle was prepared using extract and essential oil of Illicum verum Hook. F. in the presence of Tween 80 as an emulsifier. The concept of this procedure is the reduction and oxidation of $\mathrm{Ag}^{+}$into $\mathrm{Ag}^{\mathrm{o}}$. There is no studies have been found yet that prepare Ag nanoparticles using extract and essential oil of illicium verum Hook. F. This plant was chosen due to its availability that quite huge in this tropical country, Indonesia. Also, the essential oil yield of this plant is about $8-12 \% .{ }^{19}$ Based on the previous study, the essential oil of this plant has low bioactivity as antibacterial, i.e. E. Coli $(0.8 \mathrm{~mm})$ and $S$. Aureus $(1.45 \mathrm{~mm}) \cdot{ }^{20}$ With the incorporation of extract and essential oil of Illicium verum Hook. F. in the synthesis of Ag nanoparticles, it assumed can improve the antibacterial activity of $\mathrm{Ag}$ nanoparticles.

\section{EXPERIMENTAL}

Green Synthesized Ag Nanoparticle from Extract and Essential Oil of Illicium verum Hook. F. $\mathrm{Ag}$ nanoparticle was prepared using the modified green synthesis method. ${ }^{11,4}$ Chemicals that were used to prepare Ag nanoparticles were $0.5 \mathrm{AgNO}_{3}$ Pro Analysis, $1 \mathrm{~mL}$ essential oil, and surfactant Tween 80 Pro Rasayan J. Chem., 13(4), 2483-2489(2020) http://dx.doi.org/10.31788/ RJC.2020.1345792

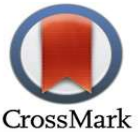


RASĀYAN J. Chem.

Vol. 13 | No. 4 |2483-2489| October - December | 2020

Analysis. The use of $\mathrm{AgNO}_{3}$ is a precursor of $\mathrm{Ag}$ nanoparticles, the essential oil and extract can be called a template, and Tween 80 acts as an emulsifier between oil and aqueous phases. Six droplets of Tween 80 were added into the mixture of $\mathrm{AgNO}_{3}$ and essential oil, the mixture was heated up to $70^{\circ} \mathrm{C}$ for $80 \mathrm{~min}$. The change of color from yellow to brown is an indication of the Ag nanoparticle has been synthesized. The final step was the separation of Ag nanoparticles from the solution through centrifugation at 6000 rpm for 30 min. ${ }^{4,11,12}$ For further purpose, this Ag nanoparticle called AgNPsE (Polymer of Chemistry Laboratory).

Almost similar to the above method, in this method, an Ag nanoparticle was prepared in the presence of extract. Nine grams of Illicium verum Hook. F. powder was dissolved in water to obtained a final concentration of $9 \mathrm{wt} \% .^{21}$ Sixty milliliters of extract were heated up to $90^{\circ} \mathrm{C}$, and $0.1 \mathrm{~g}$ of $\mathrm{AgNO}_{3}$ was added into the extract, the reaction was stopped after $80 \mathrm{~min}$. For further purposes, this Ag nanoparticle is called AgNPsMA. All Material in this research from (Basic Science Laboratory, Department of Chemistry, Faculty of Mathematics and Natural Science, Universitas Sumatera Utara).

\section{FT-IR}

The presence of a functional group was identified using FT-IR (Bruker) at the range wavenumber of 500$4000 \mathrm{~cm}^{-1}$ (Integrated Laboratory and Center for Innovation, Technology, Universitas Lampung).

\section{XRD}

The XRD analysis was conducted to determine the crystallinity and particle size of silver nanoparticles. About $200 \mathrm{mg}$ of silver nanoparticle powder was pressed on the aluminum template using the support of adhesive (Laboratory of Institut Teknologi Surabaya).

TGA/DTA (Integreted Laboratory and Center for Innovation, Tecnology, Universitas lampung).

Thermal stability of Ag nanoparticle was determined using DTG-60 Shimadzu. The measurement condition was set as the following parameter: temperature range was $30-1000^{\circ} \mathrm{C}$ with heat rate $10^{\circ} \mathrm{C} / \mathrm{min}$.

TEM (Laboratory Faculty of Mathematics and Natural Science, Universitas Gajah Mada). The nanosized Ag nanoparticle was measured using TEM JEOL JEM 1400.

\section{Antibacterial Activity of Ag Nanoparticle}

The antibacterial activity of both Ag nanoparticles was determined using the agar well dissemination method. The antibacterial activity of $\mathrm{Ag}$ nanoparticles was compared with the antibacterial of $\mathrm{AgNO}_{3}$, essential oil and extract of Illicium verum Hook. F (Laboratory Microbiology Faculty of Mathematics and Natural Science, Universitas Sumatera Utara)

\section{RESULTS AND DISCUSSION}

The preliminary study on the preparation of $\mathrm{Ag}$ nanoparticles was prepared using the green synthesis technique. This method was chosen due to its advantages, i.e. eco-friendly, compared to the other previous techniques. The basic concept of this method is the use of reducing agents and precursors. The reducing agent mostly has a specific functional group, i.e. aldehyde, hydroxyl, and carbonyl. ${ }^{22}$ Protein even can use for this purpose due to it can act as a stabilizer, as the role of its amine group. ${ }^{23}$ The obtained Ag nanoparticle in this current study has a grey color (Fig.-1).
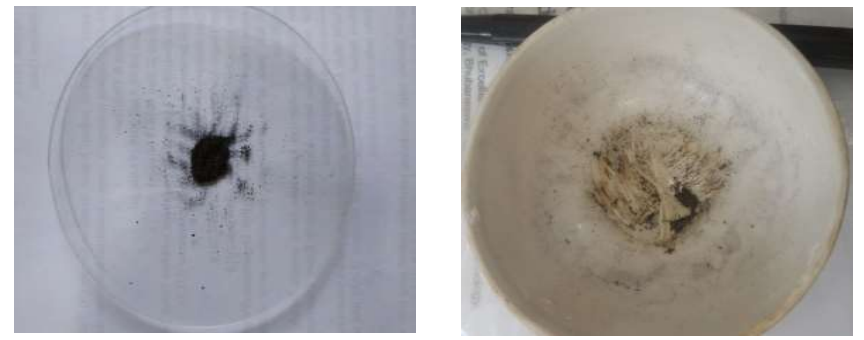

Fig.-1: Powder of (a) AgNPsE9; (b) AgNPsMA 
RASĀYAN J. Chem.

Vol. 13 | No. 4 |2483-2489| October - December | 2020

The oxidation and reduction lead to the formation of Ag nanoparticles in this green synthesis technique, where $\mathrm{AgNO}_{3}$ acts as a precursor and the extract or essential oil used as a template, also as a reducing agent. The phytochemical screening confirmed the presence of secondary metabolites in the extract and essential oil, i.e. flavonoid and terpenoid groups. The GC-MS summary in Table-1 showed the anethol was found as the major component of essential oil, about $97.03 \%$, and followed by estragole $1.58 \%{ }^{19}$

Tabel-1: A Major and Minor Compound identified by GC-MS in the Essential Oil Illicium verum Hook. F.

\begin{tabular}{c|c|c|c}
\hline No. & Compound & RT (min) & Area (\%) \\
\hline 1 & 1,4-Cyclohexadiene & 2.429 & 0.03 \\
\hline 2 & Pyrazinecarboxamide & 2.643 & 0.01 \\
\hline 3 & 1,6-Octadiene & 2.728 & 0.02 \\
\hline 4 & 1-Phellandrene & 2.856 & 0.02 \\
\hline 5 & Terpinen & 2.908 & 0.06 \\
\hline 6 & Limonene & 3.036 & 0.77 \\
\hline 7 & Cineole & 3.070 & 0.10 \\
\hline 8 & ALPHA-PINENE & 3.241 & 0.01 \\
\hline 9 & Linaloloxide & 3.369 & 0.01 \\
\hline 10 & alpha.-Fenchene & 3.480 & 0.03 \\
\hline 11 & Linalol & 3.540 & 0.11 \\
\hline 12 & TRANS-SABINENE HYDRATE & 3.968 & 0.01 \\
\hline 13 & Linalyl propionate & 4.361 & 0.12 \\
\hline 14 & Estragole & 4.446 & 1.58 \\
\hline 15 & Anisole & 4.908 & 0.09 \\
\hline 16 & Benzaldehyde & 4.993 & 0.03 \\
\hline 17 & Anethole & 5.327 & 96.83 \\
\hline 17 & cis-Geraniol & 5.934 & 0.01 \\
\hline 18 & Anisketone & 6.071 & 0.05 \\
\hline 19 & Caryophyllene & 6.242 & 0.01 \\
\hline 20 & alpha.- Farnesene & 6.412 & 0.01 \\
\hline 21 & p-Methoxypropiophenone & 6.635 & 0.01 \\
\hline 22 & beta.-Bisabolene & 6.985 & 0.01 \\
\hline 23 & Elemol & 7.370 & 0.01 \\
\hline & & &
\end{tabular}

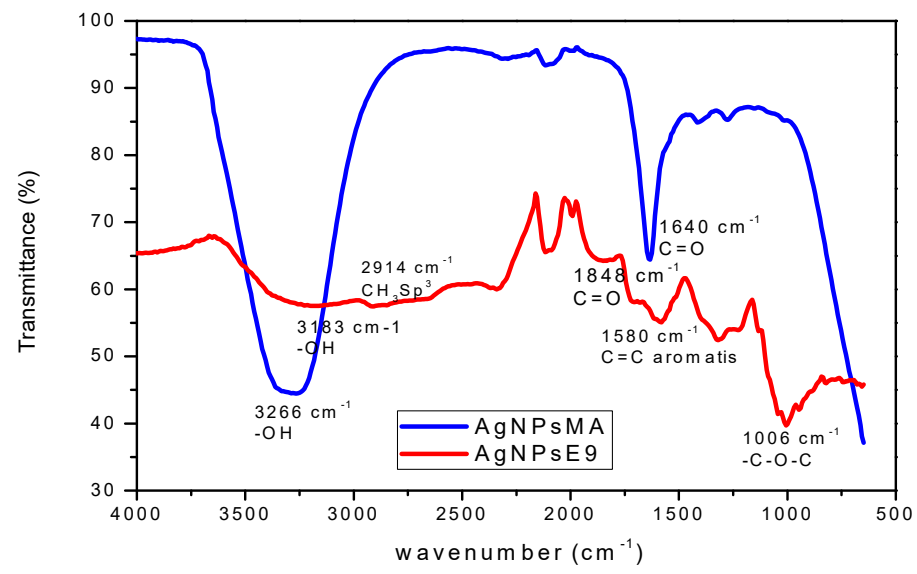

Fig.-2: FT-IR Spectra of Powder AgNPsMA and AgNPSE

Figure-2 showed the FT-IR spectra of AgNPsMA, it showed the presence of $\mathrm{C}=\mathrm{O}$ and $-\mathrm{OH}$ stretching at 1640 and $3265 \mathrm{~cm}^{-1}$, respectively. ${ }^{4,7,24,25}$ FT-IR spectra of AgNPsE showed transmittance at $3183 \mathrm{~cm}^{-1}$ corresponds stretching vibration $\mathrm{OH}_{-}^{-26}$ and presence of $\mathrm{C}=\mathrm{O}$ at $1848 \mathrm{~cm}^{-1} .^{1}$ FT-IR showed a new spectrum AgNPsE, namely at a wavelength $750 \mathrm{~cm}^{-1}$. It indicates a spectrum to AgNPsE. The other functional groups present probably belong to the compounds Illicium Verum Hook. F. 
RASĀYAN J. Chem.

Vol. 13 | No. 4 |2483-2489| October - December | 2020

XRD

The X-ray diffraction pattern of AgNPs can be seen in Fig.-3. Based on Fig. 3, the AgNPs showed the signal at $2 \theta 37^{\circ}(111), 44^{\circ}(200), 64^{\circ}(202)$, and $78^{\circ}(311) .{ }^{27,28}$ Those signals indicated the presence of $\mathrm{Ag}$, the crystallinity degree of $\mathrm{Ag}$ was $87.17 \%$ and $96 \%$ for AgNPsE and AgNPsMA, respectively. Both materials have lattice crystals as Face Center Cubic (FCC). ${ }^{25,29}$

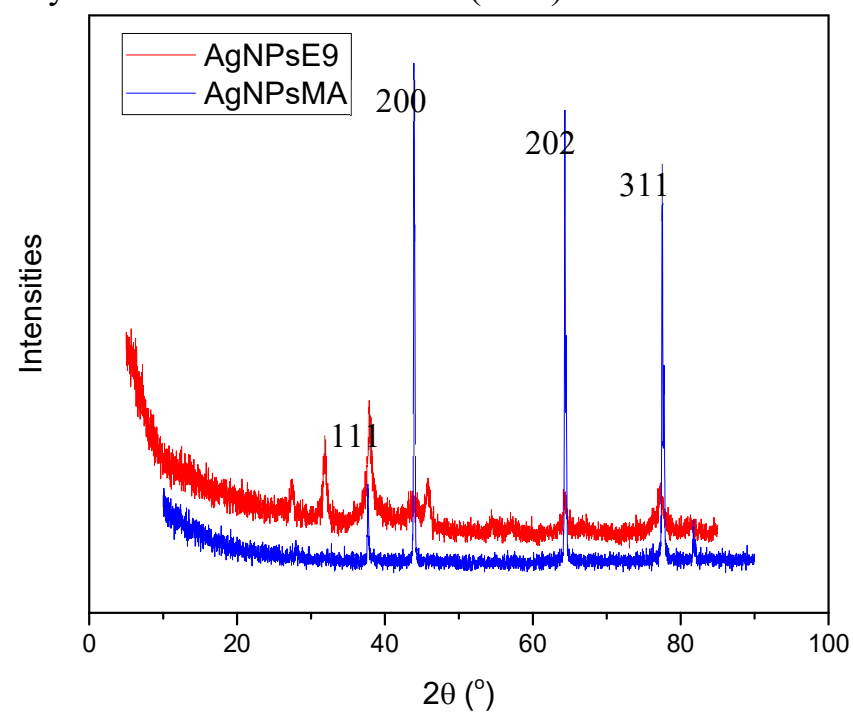

Fig.-3: XRD Pattern of AgNPsE and AgNPsMA

\section{Thermal Stability of Ag Nanoparticle}

Thermal analysis can give information about the weight loss of AgNPs at a specific temperature due to exothermic and endothermic reactions. ${ }^{30}$ Figure- 4 and 5 showed the thermal stability of AgNPsE and AgNPsMA.

AgNPsE was decomposed at $229.3{ }^{\circ} \mathrm{C}$ with the decomposition rate at $0.1 \mathrm{mg} / \mathrm{min}$ and the residue at the end process was $65.67 \%$. While AgNPsMA was decomposed at $241.3{ }^{\circ} \mathrm{C}$ with the decomposition rate at $0.033 \mathrm{mg} / \mathrm{min}$.

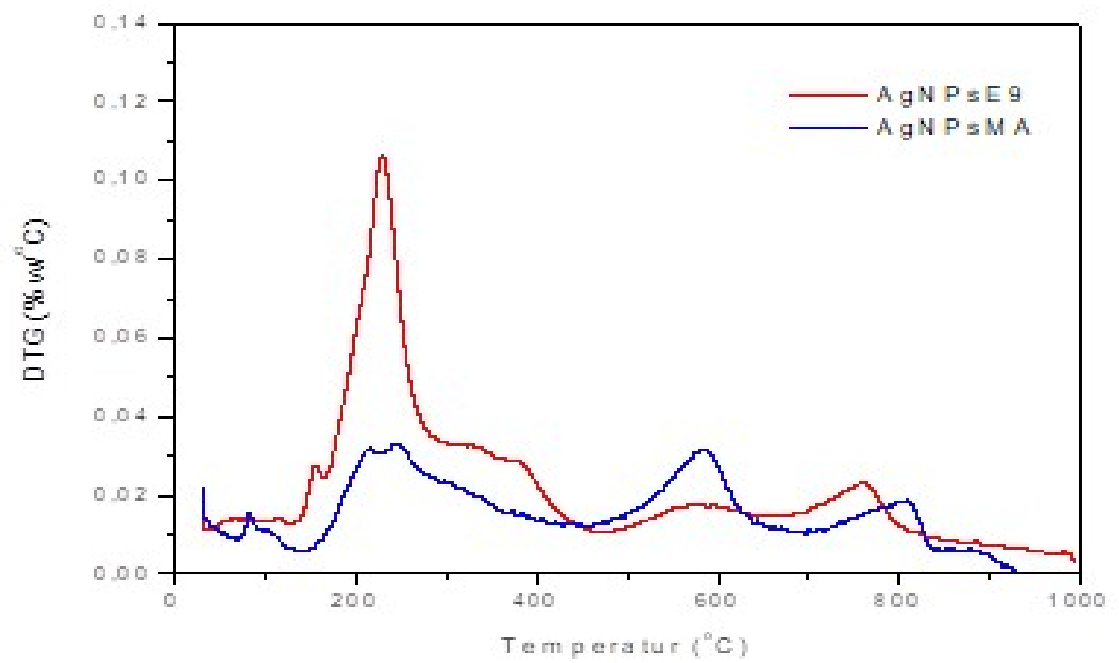

Fig.-4: DTG AgNPs9, AgNPsMA

The decomposition of AgNPsE was divided into 3 steps. The first step can be observed around $30-250^{\circ} \mathrm{C}$ that can be assumed as the water evaporation. The second step of degradation can be found at $250-550^{\circ} \mathrm{C}$ with a weight loss of about $26 \%$. And continued with the third step at $550-800^{\circ} \mathrm{C}$ with a weight loss of 
RASĀYAN J. Chem.

Vol. 13 | No. 4 |2483-2489| October - December | 2020

about 34\%. Different from AgNPsE, the Ag nanoparticle that was prepared with essential oil showed four steps of degradation. The first step was found at $30-110^{\circ} \mathrm{C}$ and then the second and third step of degradation can be found at $200-350^{\circ} \mathrm{C}$ and $350-650^{\circ} \mathrm{C}$ with the weight loss about is $25 \%$. Finally, stage observed at $650-1000^{\circ} \mathrm{C}$ with the weight loss about is $33 \%$.

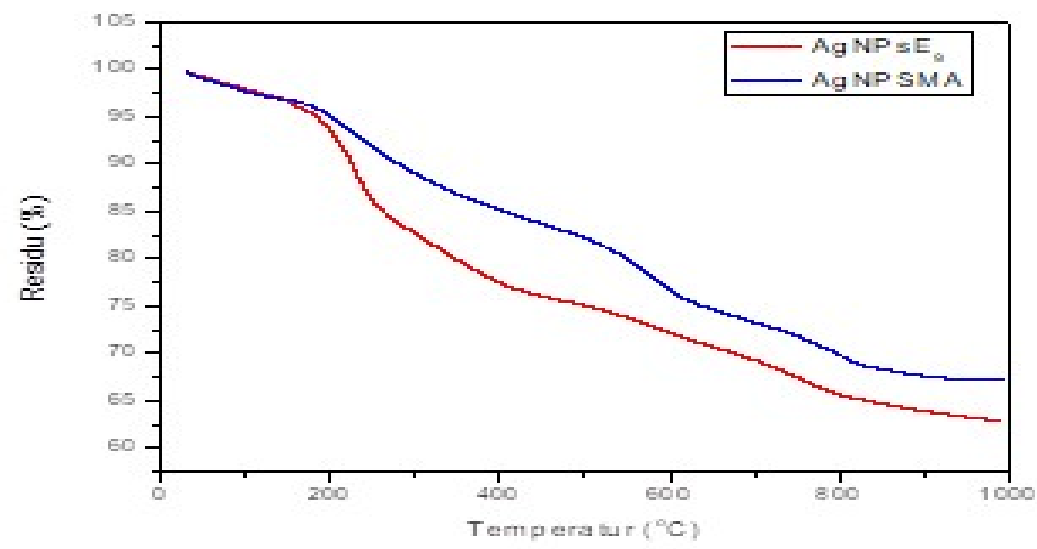

\section{TEM}

Fig.-5: TGA AgNPSE9 and AgNPSMA

Figures-6 and 7 showed the image of TEM analysis and histogram of both samples, i.e. AgNPsE and AgNPsMA. Both of them showed has a relatively good distribution of nanosize particles with spherical shapes. ${ }^{28,31,32}$ The particle size of the Ag nanoparticle was determined using ImageJ software. Based on the TEM result, the particle size was not uniform, the average diameter of AgNPsE and AgNPsMA was 11.46 and $10.98 \mathrm{~nm}$. The particle size of AgNPsMA was smaller than that prepared using an extract of Illicium verum Hook. F.
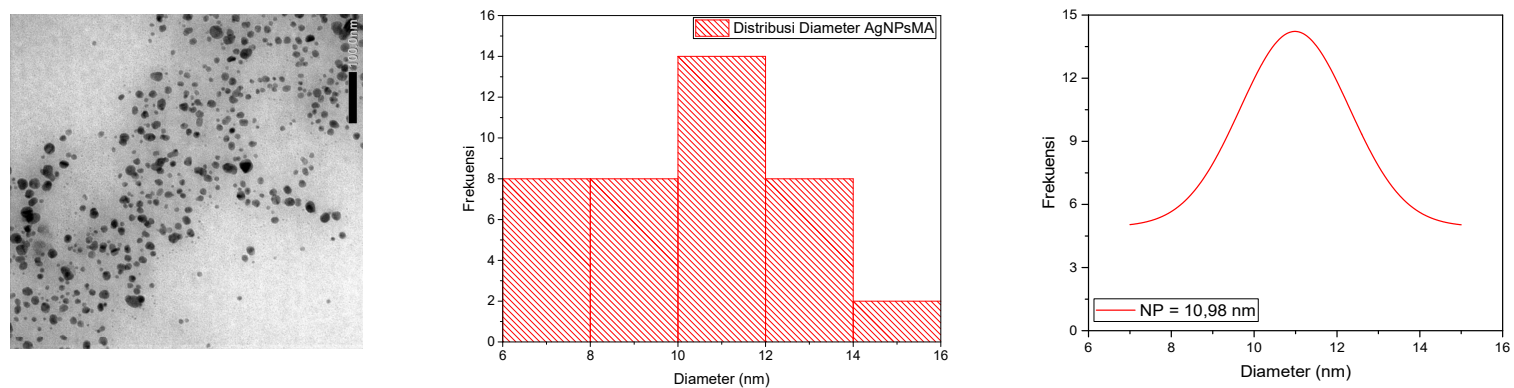

Fig.-6: TEM Image and Histogram of AgNPsMA
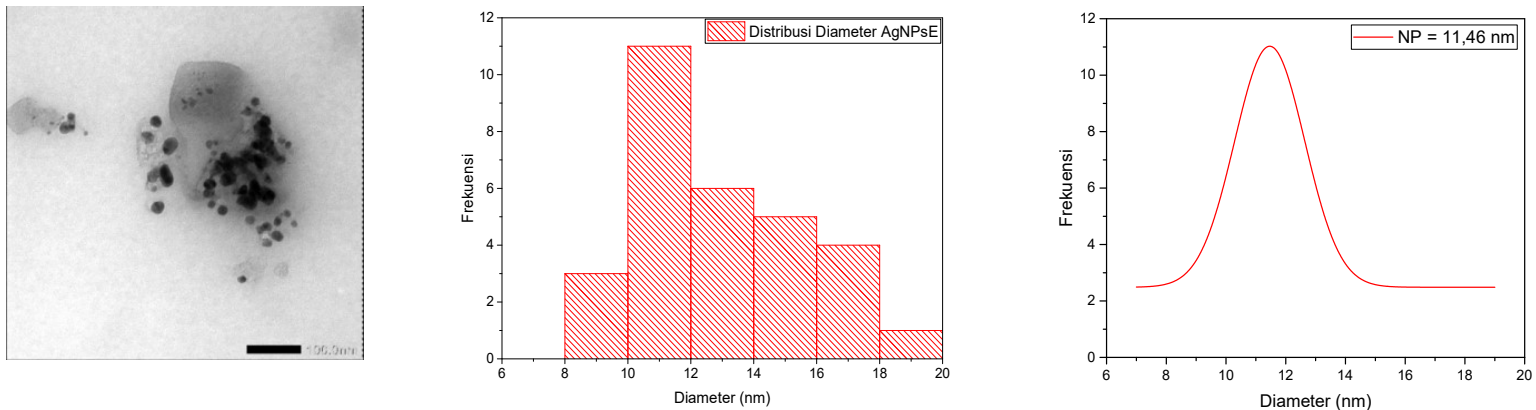

Fig.-7: TEM Image and Histogram of AgNPsMA

\section{Antibacterial Activity of Ag Nanoparticle}

The presence of a clear zone around the disc paper that has been stained with the Ag nanoparticle suspension indicated that the prepared AgNPsE and AgNPsMA have bioactivity as antibacterial. The diameter of the clear zone is an indicator to confirm how strong is the antibacterial activity of each specimen, the wider the clear zone, the strongest its antibacterial activity. 
RASĀYAN J. Chem.

Vol. 13 | No. 4 |2483-2489| October - December | 2020

Antibacterial activity of the extract was influenced by the presence of the phenolic compound and another secondary metabolite that has been identified presence in the extract. Confirmed the presence of hydroxyl group in the active secondary metabolite can improve the antibacterial activity of that compound, the mechanism was predicted by disturbing the function of the bacterial receptor. ${ }^{33}$ The phenolic in Illicium verum Hook. F. acted as a building block to anticipate pathogenic bacterial infection. ${ }^{34}$ In this study, the antibacterial activity was tested against $S$. aureus and E. coli. The antibacterial activity of each sample can be seen in Table- 2 .

Table-2: Antibacterial Activity of Ag Nanoparticle

\begin{tabular}{c|c|c}
\hline Bacteria & Sample Name & Clear Zone Diameter (mm) \\
\hline \multirow{4}{*}{$\begin{array}{c}\text { Staphylococcus } \\
\text { aureus }\end{array}$} & $\mathrm{AgNO}_{3}$ & 0.43 \\
\cline { 2 - 3 } & Essential Oil & 1.45 \\
\cline { 2 - 3 } & Extract & - \\
\cline { 2 - 3 } & $\mathrm{AgNPsMA}$ & 5.79 \\
\cline { 2 - 3 } & $\mathrm{AgNPsE}$ & 0.22 \\
\hline Escherichia coli & $\mathrm{AgNO}_{3}$ & 1.83 \\
\cline { 2 - 3 } & Essential Oil & 0.8 \\
\cline { 2 - 3 } & Extract & - \\
\cline { 2 - 3 } & $\mathrm{AgNPsMA}$ & 5.55 \\
\cline { 2 - 3 } & $\mathrm{AgNPSE}$ & 0.93 \\
\hline
\end{tabular}

\section{CONCLUSION}

The Ag nanoparticle has been prepared using a green synthesis method, with the presence of extract and essential oil of Illicium verum Hook. F. The FT-IR spectra showed the presence of $\mathrm{C}=\mathrm{O}$ and $\mathrm{O}-\mathrm{H}$ vibration. The diffractogram of XRD analysis confirmed the presence of Ag which has FCC lattice crystal and it has particle size around 10-12 nm. Size AgNPsMA smaller than AgNPsE. The obtained nanoparticle also showed a thermal stability property and its potential to be developed as an antibacterial agent.

\section{ACKNOWLEDGEMENT}

The author thanks LPDP for the financial support to perform the research. The scholarship number 20161141021374.

\section{REFERENCES}

1. M.Gopalakrishnan, A. Sheenu, B. Varghese, J. Dharani, S. Saranya, Rasayan Journal of Chemistry, 12(3), 1072(2019), DOI:10.31788/RJC.2019.1235136

2. E. Iglesias-Silva, J. Rivas, I.L.M. Leon, M.A. Lopez-Quintela, Journal of Non-Crystalline Solid, 353, 829(2007), DOI: 10.1016/j.jnoncrysol.2006.12.050

3. K. Shameli , M. Mansor Bin Ahmad, Z. Mohsen ,W.Z. Yunis, N.A. Ibrahim, A. Rustaiyan, International Jounal of Nanomedicine, 6, 581(2011), DOI:10.2147/IJN.S17112

4. A. Yadav, A. Kaushik, A. Joshi, International Journal of Life science \& Pharma Research, 8, 2250(2018), DOI:10.5897/JMA11.060

5. A. Afkhami and R. Moosavi, Journal of Hazardous Materials, 174: 398-403(2010), DOI:10.1016/j.jhazmat.2009.09.066

6. D.R. Bhumkar, M. Joshi, V.B. Sastry, Pokharkar, Pharmaceutical Research, 24, 1415(2007).

7. K. Mallikarjuna, G. Narashimha, G.R. Dillip, B. Praveen, B. Shreedhar, C. Sreelakshmi, B.V.S. Reddy, Deva, Prasad, B. Raju, Journal of Nanomaterials and Biostructures, 6, 181(2011), DOI:10.1007/s13562-019-00522-2

8. L. Ge, Q. Li, M. Wang, Ouyang, X. Li, M.M. Xing, International Jounal of Nanomedicine, 4, 2399(2014), DOI:10.2147/IJN.S55015

9. S. Achmed, M. Ahmad, B.L. Swami, S. Ikram, Jounal of Radiation Research and Applied Sciences, 9, 1(2016), DOI:10.1016/j.jjras.2015.06.006

10. P Raveendran, J. Fu, and S.L. Wallen, Journal of American Chemical Society, 125, 13940(2003), DOI:10.1021/ja029267j

11. M. Yasir, J. Singht, M.K. Tripathi, P. Sight, Sharivastava. Pharmacognosy Magazine, 13, 52(2017), DOI:10.4103/pm.pm_226_17 
RASĀYAN J. Chem.

Vol. 13 | No. 4 |2483-2489| October - December | 2020

12. M.Z.H. Khan, M.A. Thareq, M.N.A. Hossen, Roki, Journal of Engineering Scienceand Technology. 13(1), 158(2018).

13. M. Ali, B. Kim, K.D. Belfield, D. Norman, M. Brennan and G.S Ali, Materials Science and Engineering C, 58, 359(2016), DOI:10.1016/j.msec.2015.08.045

14. H.A. Ghramh, K.M. Al-Ghamdi, J. Mahyoub, E.H. Ibrahim, Journal of Asia- Pacific Entomology, 21, 205(2018), DOI:10.1016/j.aspen.2017.12.001

15. D. Jha, P.K. Thiruveedula, R. Pathak, B. Kumar, and H.K. Gautam, Materials Science and Engineering C, 80, 659(2017), DOI:10.1016/j.msec.2017.07.011

16. B. Moldovan, L. David, A. Vulcu, L. Olenic, and M. Perde- Schrepler. 2017. Materials Science and Engineering C, 79, 720(2017), DOI:10.1016/j.msec.2017.05.122

17. L. Wang, Y. Wu, J. Xie, S. Wu, and Z. Wu, Materials Science and Engineering C, 86, 1(2018), DOI:10.1016/j.msec.2018.01.003

18. S.M. Yedurkar, C.B. Maurya and P.A. Mahanwar, Journal of. Materials and Environmental Sciences, 8, 1173(2017).

19. MB. Gholivand, M. Rahimi-Nasrabadi, H. Chalabi, Analytical Letters, 42, 1382(2009), DOI: $10.1080 / 00032710902961081$

20. E.A.M. Zuhud, W.P. Rahayu, C.H. Wijaya and P.P. Sari, Jurnal Teknologi dan Industri Pangan. Vol XII, No.1, IPB, Bogor (2001).

21. Y. Routh, S. Bahera, A.K. Ojha, P.L. Nayak, Journal of Microbiology and Antimicrobials, 4(6), 103(2012), DOI: 10.5897/JMA11.060

22. K.M.M. Abou El-Nour, A. Eftaiha, A. Warthan, and R.A.A. Ammar, Arab Journal of Chemistry, 3, 135(2010), DOI: 10.1016/j.arabjc.2010.04.008

23. A.C. Templeton, W.P. Wuelfing, and Murray R. W. Accounts of Chemical Research, 33(1), 27(2000).

24. A. Lalitha, R. Subbaiya, P. Ponmurugan, International Journal of Current Microbiology and Applied Sciences, 2(6), 228(2013).

25. B. Habibi, H. Hadilou, S. Mollaei, A. Yazdinezhad, International Journal of Nano Dimension, 8(2), 132(2017), DOI: 10.22034/ijnd.2017.24954

26. G. Hongfang, Y. Huy, W. Cuang, Rsults in Physics, 7, 3130(2017), DOI:10.1016/j.rinp.2017.08.032

27. I. Fierascu, I.M. Georgiev, A. Ortan, R.C. Fierascu, S.M. Avramescu, D. Lonescu, A. Sutan, A. Brinzan and L.M Ditu, Scientific Report, 17, 12482(2017), DOI:10.1038/s41598-017-12804-7

28. O.R.O Luis, R.H. Delgadillo, R.I.S. Najera, G.A.M. Castanon, N.N. Martiniez, M.C.S.N Navarro, F. Ruiz , and C.C. Romero, Journal of Nanomaterials, Article ID 9204537, 10 pages(2016), DOI: $10.1155 / 2016 / 9204573$

29. G.M. Srirangam \& K.P. Rao, Rasayan Journal of Chemistry, 10(1), 46(2017), DOI:10.7324/RJC.2017.1011548

30. Khalil, I. Mutasim, M. Maha, M. Aisha, P.L. Joselito, Arabian Journal of Chemistry, 7(6), 1178(2014), DOI:10.1016/j.arabjc.2013.10.025

31. G.A. Velencia, L.C.O. Vercik, R. Ferarri, A. Vercik, Starch-Journal, 65, 1(2013), DOI:10.1002/star.201200252

32. N. Elisma, A. Labanni, Emriadi, Y. Rilda, M. Asrofi, S. Arief, Rasayan Journal of Chemistry, 12(4), 1752(2019), DOI: 10.31788/RJC.2019.1245347

33. A.J.L.M. Bhorgin and U.M. Perumal, World Journal of Pharmacy and Pharmaceutical Science, 5(9), 2040(2016), DOI: 10.20959/wjpps20169-7676

34. R.V. Bluma and M.V. Etcheverry, Food Microbiol, 25(2), 324(2008), DOI: 10.1016/j.fm.2007.10.004

[RJC-5792/2020] 